\title{
新型多孔导电陶瓷负载银阴极在锌空气电池中的应用
}

\author{
翁晓琳 ${ }^{1}$, 刘佩佩 ${ }^{1}$, 张亚鹏 ${ }^{1}$, 刘 江 ${ }^{1}$, 刘美林 ${ }^{1,2}$
}

(1. 华南理工大学 环境与能源学院, 新能源研究所, 广州市能源材料表面化学重点实验室, 广州 510006; 2. 美国 佐治亚理工学院 材料科学与工程系, 亚特兰大 GA 30332-0245, 美国)

摘 要: 锌空气电池具有能量密度高、成本低及环保等优势, 其空气电极的优劣对电池的输出性能起到决定性的作 用。本研究采用一种新型的多孔钲钛矿氧化物 $\mathrm{La}_{0.7} \mathrm{Sr}_{0.3} \mathrm{CoO}_{3-\delta}(\mathrm{LSC})$ 作为陶瓷基底, 负载银纳米颗粒作为催化剂, 研 究其作为锌空电池空气电极的性能。通过调整制备过程中造孔剂(淀粉)的含量, 优选出性能最佳的 Ag-LSC 空气电 极(阴极), 与锌阳极组装成锌空气电池, 进行电化学性能测试。结果表明, 当 LSC 基底的孔隙率为 32\%且银含量 $30 \mathrm{mg} / \mathrm{cm}^{2}$ 时, 制备的多孔陶瓷负载银阴极组装的锌空气电池功率密度最高 $\left(141 \mathrm{~mW} / \mathrm{cm}^{2}\right)$ 。在 $\mathrm{Ag}-\mathrm{LSC}$ 空气电极表 面涂一层聚四氟乙烯(PTFE)疏水材料后, 锌空气电池的使用寿命得到显著延长。

关 键 词: 锌空气电池; 空气电极; 银纳米颗粒; 多孔钴酸锶镧基底

中图分类号: 0647 文献标识码: A

\section{A Novel Porous Electronic Conducting Ceramics Loaded with Silver Nano Particles as Cathode for Zinc-Air Batteries}

\author{
WENG Xiao-Lin ${ }^{1}$, LIU Pei-Pei ${ }^{1}$, ZHANG Ya-Peng ${ }^{1}$, LIU Jiang $^{1}$, LIU Mei-Lin ${ }^{1,2}$ \\ (1. Guangzhou Key Laboratory for Surface Chemistry of Energy Materials, New Energy Research Institute, School of Envi- \\ ronment and Energy, South China University of Technology, Guangzhou 510006, China; 2. School of Materials Science and \\ Engineering, Georgia Institute of Technology, Atlanta GA 30332-0245, USA)
}

\begin{abstract}
Zinc-air battery has great advantages such as high energy density, low cost and environmentally friendliness. Air electrode plays an important role in electrochemical performance of a zinc-air battery. In this paper, we report our study of a novel air electrode on which a porous perovskite ceramic $\mathrm{La}_{0.7} \mathrm{Sr}_{0.3} \mathrm{CoO}_{3-\delta}$ (LSC) with Ag nanoparticles directly grown. The porous LSC is used as substrate while Ag as catalyst. The porous structure of substrate attributes to the amount and dispersion of $\mathrm{Ag}$ nanoparticles which affect the electrochemical performance of air electrode. Therefore, the property of the Ag-LSC electrode is optimized by adjusting the mass content of pore-former (starch). Experimental results show that the Ag-LSC electrode, with a porosity of $\sim 32 \%$ and a $\mathrm{Ag}$ load of $\sim 30 \mathrm{mg} / \mathrm{cm}^{2}$, exhibits the best performance in all tested samples, and a zinc-air battery assembled with such air electrode gives the maximum power density of $141 \mathrm{~mW} / \mathrm{cm}$. What's more, in order to ensure the gas diffusion channels, the hydrophilicity and hydrophobicity of the cathode is modified with PTFE to prevent flooding. After all that, the life-time of the zinc-air battery, with optimization by coating a PTFE layer as hydrophobic agent on the surface of the selected Ag-LSC electrode, prolongs significantly.
\end{abstract}

收稿日期：2017-09-28; 收到修改稿日期：2017-11-18

基金项目: 国家自然科学基金(21276097); 广东省公益研究及能力建设专项基金(2014A010106008); 广东省珠江人才计划 引进创新创业团队项目(2014ZT05N200); 国家自然科学基金委-广东省联合基金(U1601207)

National Natural Science Foundation of China(21276097); Special Funds of Guangdong Province Public Research and Ability Construction (2014A010106008); Guangdong Innovative, Entrepreneurial Research Team Program (2014ZT05N200); Joint Funds of National Science Foundation of China and Guangdong Province (U1601207)

作者简介: 翁晓琳(1993-), 女, 硕士研究生. E-mail: wxl_rosaline@163.com

通讯作者: 刘 江, 教授. E-mail: jiangliu@scut.edu.cn 
Key words: zinc-air battery; air electrode; silver nanoparticle; porous $\mathrm{La}_{0.7} \mathrm{Sr}_{0.3} \mathrm{CoO}_{3-\delta}$ substrate

锌空气电池属于金属空气电池，具有理论能量 密度高(1086 Wh/kg), 安全性好、成本低及环境友好 等优点 ${ }^{[1-4]}$, 可直接在空气氛围下使用, 比锂空气电 池更接近实际应用 ${ }^{[5-6]}$ 。因锌空气电池放电平稳, 目 前被广泛应用于助听器、导航灯等低功率输出器件 中。Sebastian 等 ${ }^{[7]}$ 通过比较相同大小的锌空气电池 和商业化的锌锰碱性电池, 发现锌空气电池放电容 量更高。但锌空气电池还没有在电源领域得到广泛 的商业化应用。

锌空气电池常用的空气电极由三部分组成: 气 体扩散层、集流体及催化层。最早出现的锌空气电 池采用多孔铂碳电极作为空气电极，目前商业化的 空气电极主要以碳为导电基底, 添加聚四氟乙烯 (PTFE)构建疏水通道, 还可以利用 PTFE 的黏合作 用将催化剂黏合到阴极基底 ${ }^{[8-9]}$ 。为了提高空气的氧 还原性能, 大部分研究集中在氧还原催化剂上。常 见的氧还原催化剂包括贵金属、金属氧化物、碳基 材料、金属氧化物与纳米碳的复合材料、金属-氮化 合物、导电聚合物等。其中, 铂系催化剂是氧还原反 应最理想的催化剂 ${ }^{[10-12]}$ 。但铂的价格昂贵, 因此大 量研究集中在将更便宜的贵金属银用作氧还原催化 剂。银在碱性条件下具有对电子传递良好的氧还原催 化性能，其交换电流密度与铂接近 ${ }^{[13-18]}$ 。Wang 等 ${ }^{[16]}$ 采用在碳基底上分布直径约 $5.4 \mathrm{~nm}$ 的银纳米颗粒制 备阴极，用于阴离子交换膜直接葡萄糖燃料电池 (AEM-DGFC), 在 $80^{\circ} \mathrm{C}$ 下最大功率密度为 $86 \mathrm{~mW} / \mathrm{cm}^{2}$ 。 Kaempgen 等 ${ }^{[19]}$ 采用单壁碳纳米管为基底附着银纳米 颗粒作为空气电极, 银颗粒尺寸为 3 5 nm 时, 制备 出的锌空气电池串联 $1 \mathrm{k} \Omega$ 电阻后放电, 放电平台 $1.0 \mathrm{~V}$, 锌电极的实际比容量达 $515 \mathrm{mAh} / \mathrm{g}$ 。

电池放电时, 空气电极上的氧还原反应涉及三 个相, 即气相、液相(离子导电相)和固相(电子导电 相), 氧还原反应发生在三相界处。因此, 为提高电

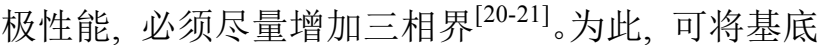
制成多孔结构, 将催化剂颗粒担载在多孔基底的孔 壁(或内表面)上，这样能显著增大基底的比表面积， 进而增加三相界。常用的碳材料基底在碱性溶液高 电位下不稳定，易发生腐蚀导致多孔结构被破坏， 致使催化剂从基底表面脱落并聚集, 催化活性降低, 而且铂等贵金属还会加快碳基底的腐蚀速度。所以 需要选取更合适的催化剂基底, 增加反应活性位点, 提高催化剂的稳定性, 以提高锌空气电池的输出性 能 ${ }^{[22]}$ 。钙钛矿 $\mathrm{ABO}_{3}$ 型复合氧化物 $\mathrm{La}_{0.7} \mathrm{Sr}_{0.3} \mathrm{CoO}_{3-\delta}(\mathrm{LSC})$
在室温下具有较高的电导率 $\left(10^{2} \sim 10^{3} \mathrm{~S} / \mathrm{cm}\right)$, 是良好 的离子和电子导体, 而且作为一种陶瓷氧化物在碱 性溶液中保持稳定 ${ }^{[23-24]}$, 具备作为阴极基底的条 件。本工作研究多孔陶瓷基底 LSC 上负载 $\mathrm{Ag}$ 纳米 颗粒(Ag-LSC)作为锌空气电池的空气电极。通过调 整制备过程中造孔剂和银的含量, 对空气电极的结 构进行优化。在室温下对组装的锌空气电池进行电 化学性能测试, 然后通过表面涂覆疏水层调控反应 位点的亲、疏水性以提高使用寿命，并对实验结果 进行了讨论和分析。

\section{1 实验方法}

\section{1 空气电极的制备}

按照 $\mathrm{La}_{0.7} \mathrm{Sr}_{0.3} \mathrm{CoO}_{3-\delta}$ 中各金属的化学计量比, 用电子天平(FA2004/V, 上海精密科学仪器)分别称 取 $\mathrm{La}_{2} \mathrm{O}_{3} 、 \mathrm{SrCO}_{3}$ 和 $\mathrm{Co}_{3} \mathrm{O}_{4}$ 三种试剂, 置于球磨罐中, 加无水乙醇至没过粉末, 加玛瑙珠后球磨 $10 \mathrm{~h}$, 再加 入一定含量(占 LSC 的质量比分别为 $8 \% 、 15 \%$ 和 $20 \%$ )的造孔剂(淀粉)球磨 $1 \mathrm{~h}$, 在红外灯下烘干粉 末。将干燥后的粉末置于玛瑙研钭中, 加入聚乙烯 醇缩丁醛 PVB(占 LSC 的质量比为 $3 \%$ ) 粘结剂, 在研 钵中研磨均匀后烘干。将此粉末每次称取 $0.5 \mathrm{~g}$, 置 于直径为 $13 \mathrm{~mm}$ 的圆柱形压片模具中, 在压片机上 (FW-4A, 天津市光学仪器厂)采用约 $4 \mathrm{MPa}$ 的压力 压出圆片, 最后将圆片在空气气氛中 $1100^{\circ} \mathrm{C}$ 下烧结 $12 \mathrm{~h}$, 得到直径 $\phi 11 \mathrm{~mm} \times 1.3 \mathrm{~mm}$ 的 LSC 陶瓷基底。 采用阿基米德法 ${ }^{[25]}$ 测试其孔隙率。

将多孔 LSC 浸入 $1 \mathrm{~mol} / \mathrm{LAgNO}_{3}$ 溶液中 $20 \mathrm{~s}$, 取 出后抽真空干燥, 在 LSC 基底的孔壁和表面上沉积 了一层 $\mathrm{AgNO}_{3}$, 此过程为浸渍过程, 沉积物质的量 可通过浸渍次数来调控。将浸渍后的陶瓷圆片在 $400^{\circ} \mathrm{C}$ 下煅烧 $2 \mathrm{~h}$, 硝酸银分解, 得到负载在 LSC 基 底上的银颗粒 Ag-LSC 空气电极。

\section{2 锌空气电池的组装及电化学性能测试}

在 $4 \mathrm{~cm} \times 4 \mathrm{~cm} \times 6 \mathrm{~cm}$ 规格的有机玻璃材质夹 具底部添加 $8.5 \mathrm{~g}$ 锌粉 (深圳中金岭南科技有限公司, $99.95 \%, 30 \sim 200$ 目), 并在锌粉中间放置长度为 $1 \mathrm{~cm}$ 的磁力摚拌子, 用不锈钢网集流引出电流; 在锌粉 上方盖上玻璃纤维隔膜, 滴加 $3 \mathrm{~mL}$ 浓度为 $6 \mathrm{~mol} / \mathrm{L}$ 的 $\mathrm{KOH}$ 溶液, 使隔膜浸润电解质溶液, 然后在隔膜 上方放置空气电极, 用银浆在空气电极上附着银线, 引出阴极电流。如图 1 所示, 将电池材料用夹具组装 

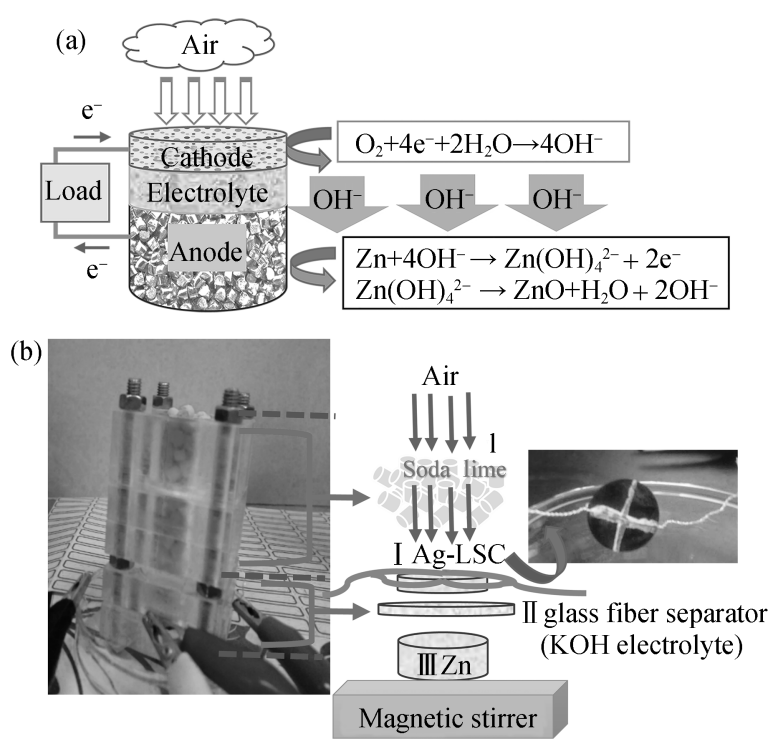

图 1 锌空气电池的工作原理示意图(a)及实物装置图(b)

Fig. 1 Schematic diagram of mechanism (a) and device (b) of the zinc-air battery

成类似三明治结构的锌空气电池, 并在电池上方添加 钠石灰(松散多孔圆柱状固体, 含有大约 $75 \mathrm{wt} \%$ 氢氧 化钙, $20 \mathrm{wt} \%$ 水, $3 \mathrm{wt} \%$ 氢氧化钠, $1 \mathrm{wt} \%$ 氢氧化钾)作空 气过滤器, 去除空气中的二氧化碳和水分, 防止二氧 化碳与电解液形成的碳酸盐堆积堵塞阴极孔洞 ${ }^{[26-27]}$ 。

在常温及空气氛围下, 将锌空气电池置于磁力 搅拌器(德国 IKA C-MAG HS4)上, 调整转速至 $500 \mathrm{r} / \mathrm{min}$, 用辰华电化学工作站进行电化学性能测 试。在开路状态下进行交流阻抗测试, 测试频率范 围为 $0.01 \sim 100 \mathrm{kHz}$, 信号幅度为 $10 \mathrm{mV}$ 。电池的电 流-电压 $(I-V)$ 曲线通过线性扫描伏安法进行测试, 扫描范围为开路电压到 0 , 扫描速率为 $0.05 \mathrm{~V} / \mathrm{s}$, 然 后将电池用计时电位法进行恒流放电测试。

\section{3 性能表征}

采用德国 BRUKER 公司的 D8 ADVANCE 型 X 射线衍射仪 $(\mathrm{XRD}, \mathrm{Cu}-\mathrm{K} \alpha)$ 对制备的空气电极的晶体 结构进行表征分析, 在 $35 \mathrm{kV} 、 30 \mathrm{~mA}$ 和 $\lambda=1.54184 \mathrm{~nm}$ 条件下测试; 采用日本 SU800 公司的扫描电镜(SEM)
对电池的空气电极的微观结构进行表征; 电池放电 前后, 将 Ag-LSC 用导电胶粘在样品台上, 采用日本 ULVAC-PHI 公司的 X 射线光电子能谱(XPS, $\mathrm{Al} \mathrm{K \alpha}$, $h v=15 \mathrm{keV}$ )在超高压真空中进行近表面化学分析。

\section{2 结果与讨论}

\section{1 性能表征}

用阿基米德法对采用质量比为 $8 \%$ 、15\%和 $20 \%$ 淀粉造孔剂制备的 LSC 基底孔隙率进行测试，得到 的孔隙率分别为 $15 \% 、 32 \%$ 和 40\%。图 2 是各基底 截面的 SEM 照片, 从图中可以看出, 所制备的 LSC 基底为多孔结构, 随着造孔剂添加量的增加, 基底 的孔隙率有明显提高。适当提高基底的孔隙率，能 提供更大的比表面积, 增加三相界的反应活性位 点。但孔隙率过高也会导致基底的结构疏松, 机械 强度降低, 且三相界减少和导电率下降。

图 3 是孔隙率为 32\%多孔 LSC 钻钛矿基底负载 $\mathrm{Ag}$ 颗粒 $10 \mathrm{mg} / \mathrm{cm}^{2}$ 前(a)后(b)的截面 SEM 照片。对 比图 3(a)和(b) 可知, $\mathrm{Ag}$ 可以均匀地负载在多孔 LSC 基底的孔壁或内表面上, 负载 $\mathrm{Ag}$ 后材料依旧保持 多孔结构, 而且在无稳定剂情况下, Ag 颗粒与 LSC 基底能够保持紧密接触, 从而降低 $\mathrm{Ag}$ 颗粒的表面 能, 使其能够保持在纳米尺度。 $\mathrm{Ag}$ 颗粒均匀负载在 多孔 LSC 基底的孔壁或内表面上, 为整个阴极提供 了足够的活性组分及活性表面。 $\mathrm{Ag}$ 与 LSC 紧密结 合, 还使电子在两者之间更快地流动转移。

$\mathrm{Ag}-\mathrm{LSC}$ (基底孔隙率为 $32 \%$ ，担载 $\mathrm{Ag} 10 \mathrm{mg} / \mathrm{cm}^{2}$ ) 阴极材料的 XRD 图谱见图 4。在 $2 \theta=23.18^{\circ}, 32.90^{\circ}$, $33.12^{\circ}, 40.63^{\circ}, 47.38^{\circ}, 58.74^{\circ}, 58.88^{\circ}, 68.99^{\circ}$ 及 $69.51^{\circ}$ 处的特征衍射峰分别对应 LSC(JCPDS No. $89-4462)$ 的(012), (110), (104), (202), (024), (300), (214), (220)及 (208)晶面; 同时在 $2 \theta=38.12^{\circ}, 44.31^{\circ}$, $64.45^{\circ}$ 及 $77.41^{\circ}$ 处的特征衍射峰分别对应 $\operatorname{Ag}(\mathrm{JCPDS}$ No. 87-0718)的(111), (200), (220)及(311)晶面。另外,
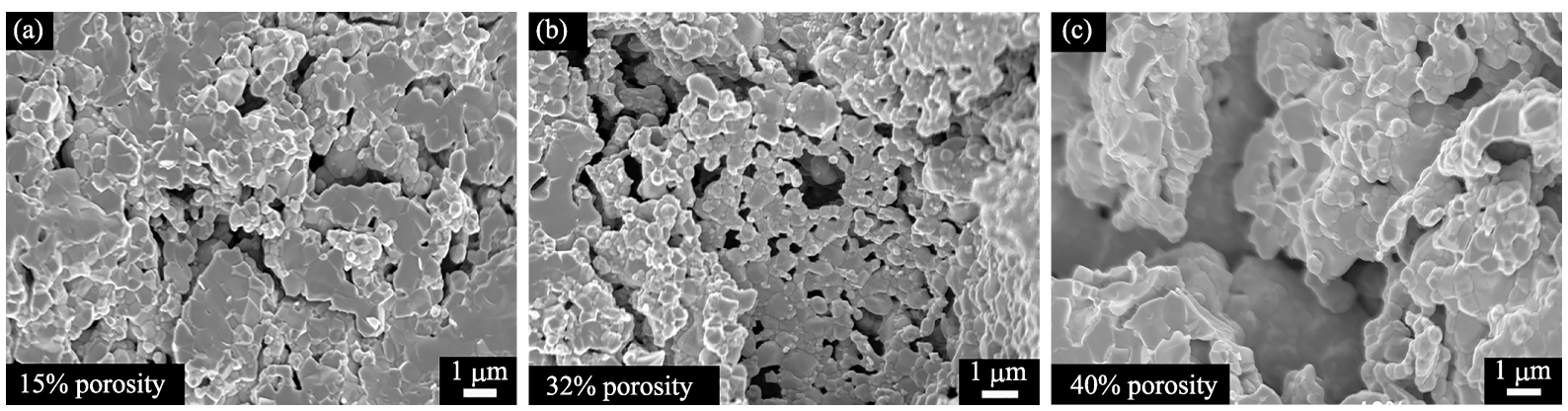

图 2 不同孔隙率的 LSC 钙钛矿基底的截面 SEM 照片

Fig. 2 Cross-sectional SEM images of the LSC substrate with different porosity 


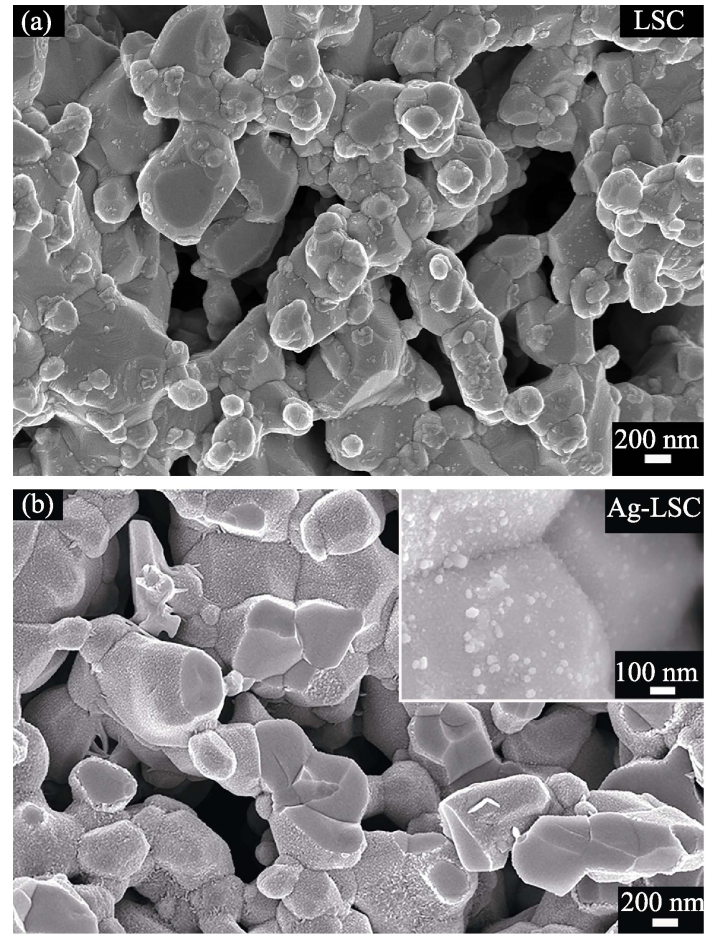

图 $3 \mathrm{LSC}$ 负载 $\mathrm{Ag}$ 前(a)后(b)的 SEM 照片

Fig. 3 SEM images of LSC (a) and Ag-LSC (b) (porosity $32 \%$, loaded Ag $10 \mathrm{mg} / \mathrm{cm}^{2}$ )

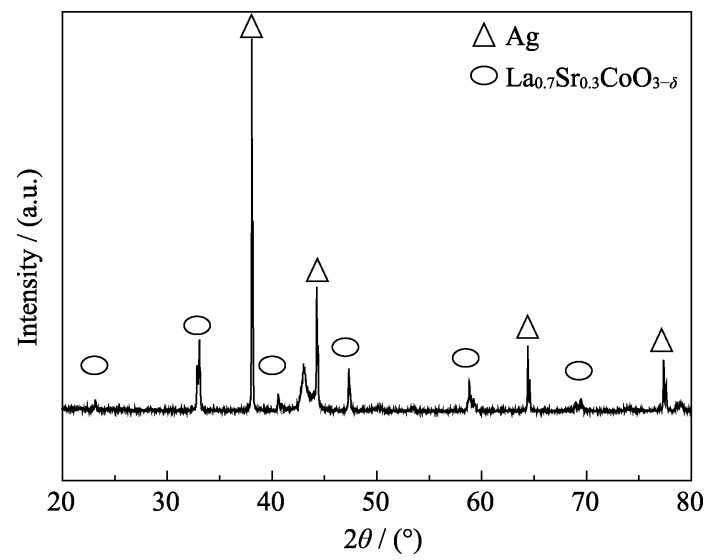

图 4 Ag-LSC 阴极的 XRD 图谱

Fig. 4 XRD patterns of Ag-LSC cathode (porosity 32\%, loaded Ag $10 \mathrm{mg} / \mathrm{cm}^{2}$ )

图谱中没有其他杂质峰出现, 表明 $\mathrm{Ag}$ 和 LSC 没有 发生化学反应，各自保持原有的相及其相应的性质。

\section{2 电化学测试}

图 5 所示为不同孔隙率、银担载量均为 $10 \mathrm{mg} / \mathrm{cm}^{2}$ 的 LSC 基底阴极组装成的锌空气电池的电化学输 出性能(a)及相应电池在开路情况下测得的阻抗谱 (b)。从图 5 (a) 可知，基底孔隙率分别为 $15 \% 、 32 \%$ 和 $40 \%$ 的阴极 (银担载量均为 $10 \mathrm{mg} / \mathrm{cm}^{2}$ ) 组装 的锌空气电池, 最大功率密度分别为 $17 、 71$ 和 $42 \mathrm{~mW} / \mathrm{cm}^{2}$, 显然, 在相同的银担载量下, LSC 基底 孔隙率为 $32 \%$ 的阴极所对应的电池具有最好的电化
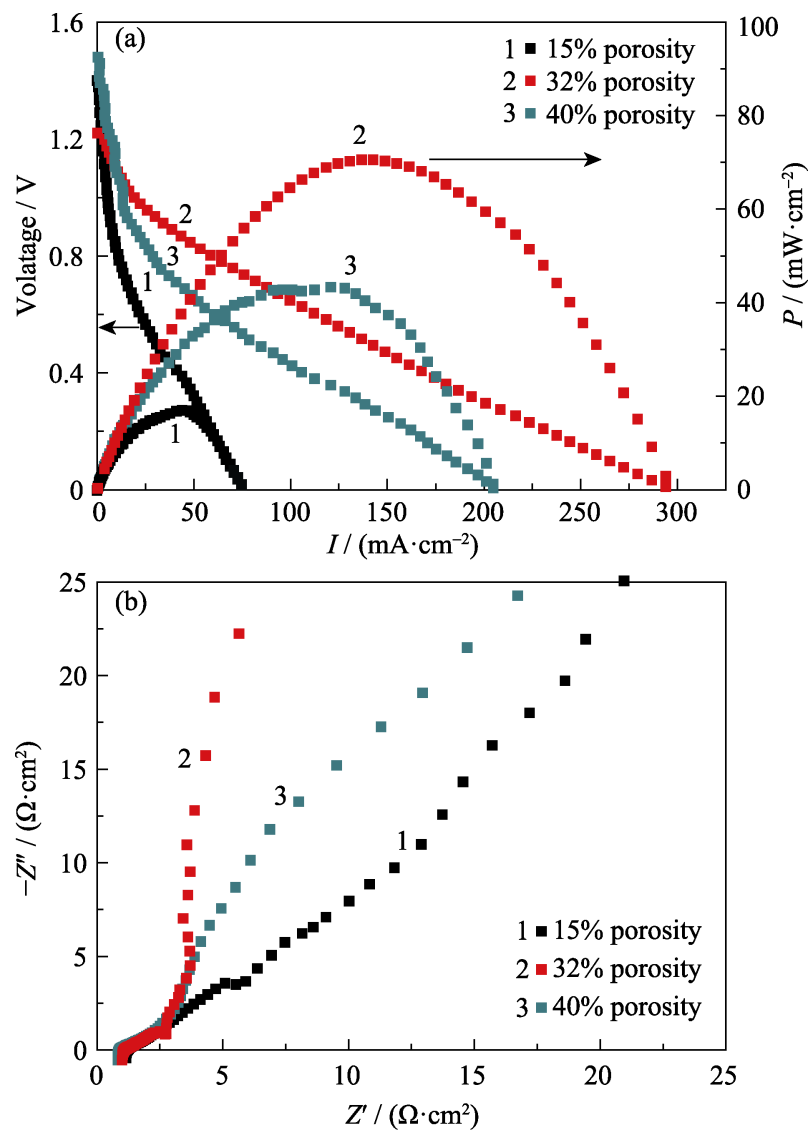

图 5 不同孔隙率的阴极(银担载量均为 $10 \mathrm{mg} / \mathrm{cm}^{2}$ )组装的 锌空气电池输出性能图谱(a)及交流阻抗图(b)

Fig. 5 Output performances (a) and impedance spectra (b) of the zinc-air battery with cathode (loaded $\mathrm{Ag} 10 \mathrm{mg} / \mathrm{cm}^{2}$ ) of different porosity

学性能。由图 5(b)可知, 所有电池的欧姆阻抗均接 近 $1 \Omega \cdot \mathrm{cm}^{2}$ ，而界面阻抗都表现出扩散效应。

图 6 所示为孔隙率为 32\%的 LSC 基底上, $\mathrm{Ag}$ 担 载量分别为 $4 、 10 、 30 、 40 \mathrm{mg} / \mathrm{cm}^{2}$ 的阴极组装的锌 空气电池的输出性能, 可见, 对应电池的最大功率

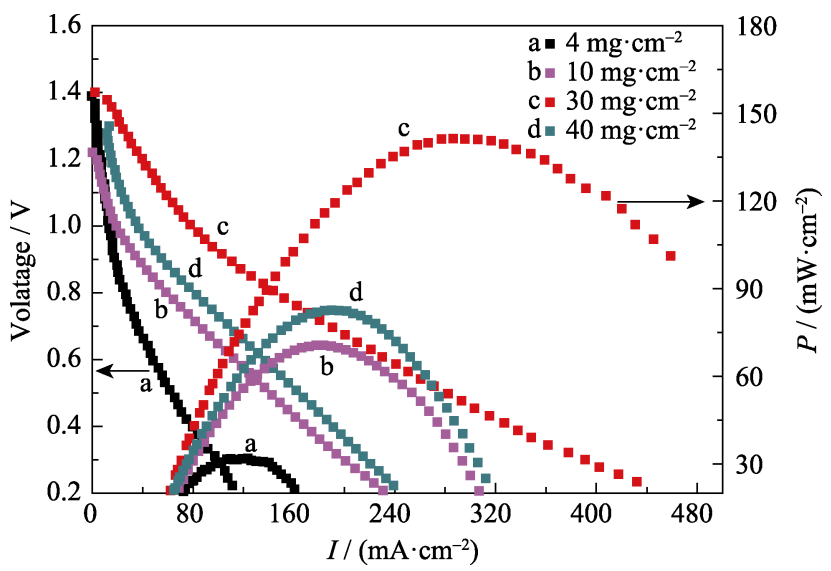

图 6 不同含银量的阴极(LSC 基底孔隙率为 32\%)组装的锌 空气电池输出性能

Fig. 6 Output performances of the zinc-air batteries with cathodes of different Ag contents (porosity 32\%) 
密度分别为 $31 、 71 、 141$ 和 $83 \mathrm{~mW} / \mathrm{cm}^{2}$ 。当 $\mathrm{Ag}$ 担 载量比较少时, 银是以分散颗粒的形式附着在 LSC 基底的孔壁或内表面上的, 随着 $\mathrm{Ag}$ 担载量的增加, 银颗粒数目增多, 催化的活性位点也增多, 电化学 活性面积增加。但当银担载量增加到一定程度后, 颗粒之间相互连接, 相互覆盖, 反而减少了阴极 反应的活性面积, 导致电池输出性能降低。上述结 果表明, 基底 LSC 的孔隙率为 $32 \%$, 且用银担载量 为 $30 \mathrm{mg} / \mathrm{cm}^{2}$ 的阴极组装的锌空电池具有最优的输 出性能 $\left(141 \mathrm{~mW} / \mathrm{cm}^{2}\right)$ 。这个数据明显高出已报道的 以 $\mathrm{Ag}$ 作为催化剂的锌空电池最大输出功率密度。 例如, Han 等 ${ }^{[28]}$ 采用 $\mathrm{Ag} / \mathrm{C}$ 纳米颗粒作为锌空电池阴 极催化剂, 阴极基底为美国 Cabot 公司的 VulcanXC-72R 碳纸 $\left(\mathrm{Ag}\right.$ 担载量为 $\left.30 \mathrm{mg} / \mathrm{cm}^{2}\right), 35^{\circ} \mathrm{C}$ 下得到电池的功率密度为 $34 \mathrm{~mW} / \mathrm{cm}^{2}, 80^{\circ} \mathrm{C}$ 下锌空 电池的功率密度为 $72 \mathrm{~mW} / \mathrm{cm}^{2}$ 。

与已有的银基阴极锌空气电池研究报道相比, 本工作的锌空气电池所呈现的优良输出性能是因为 采用了陶瓷基 LSC 基底。钻铁矿型 LSC 与 $\mathrm{Ag}$ 都 是面心立方结构, LSC 控制着 $\mathrm{Ag}$ 表面的原子排列, 不同原子排列结构的单晶面对指定反应有不同的电 催化性能; 具有开放结构和高表面能的高指数晶面, 其电催化活性和稳定性均显著优于原子紧密排列、

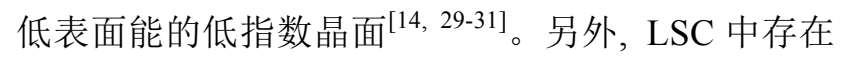
过渡金属 $\mathrm{Co}$, 据报道 ${ }^{[32-35]}, \mathrm{AgCo}$ 合金或 $\mathrm{Ag}-\mathrm{Co}_{3} \mathrm{O}_{4}$ 材料具有比纯 $\mathrm{Ag}$ 更好的 ORR 电催化活性。这是由 于相比 Ag, Ag-Co 与吸附氧之间存在更强的相互作 用, 从而促进氧还原过程。

图 7 是不同电流密度下, 以 $\mathrm{Ag}-\mathrm{LSC}$ (孔隙率 $32 \%$, 银负载量 $30 \mathrm{mg} / \mathrm{cm}^{2}$ ) 为阴极制备的锌空气电 池的放电曲线图, 每 $5 \mathrm{~min}$ 更换放电电流密度, 当 电流密度升到 $50 \mathrm{~mA} / \mathrm{cm}^{2}$ 下恒流放电, 电池仍具有

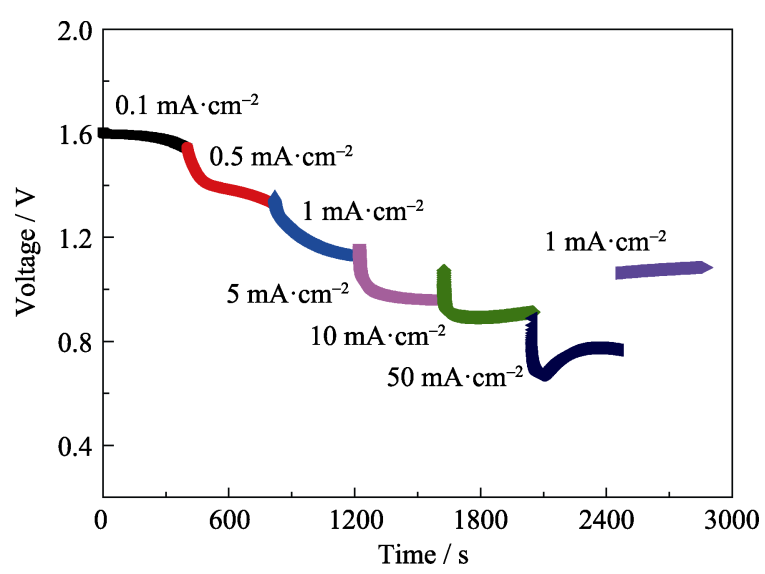

图 7 不同电流密度下锌空气电池放电性能曲线图

Fig. 7 Discharge curve of the zinc-air battery discharged at different current densities (porosity $32 \%$, loaded Ag $30 \mathrm{mg} / \mathrm{cm}^{2}$ )
接近 $0.8 \mathrm{~V}$ 的放电电压, 当电流密度回到 $1 \mathrm{~mA} / \mathrm{cm}^{2}$ 时, 电池回归到之前的放电平台, 由此可见电池在 不同电流工作条件下切换时, 具有一定的稳定性。

\section{3 添加 PTFE 对锌空气电池寿命的影响}

$\mathrm{Ag}$-LSC 阴极中的 $\mathrm{Ag}$ 和 LSC 都是亲水的, 与水 性电解液接触一段时间后, 电解液中的水会在毛细 作用下浸润阴极的所有表面，从而“淹没”表面活性 点, 为此, 需要对电极表面进行适当的疏水处理。为 调控反应位点的亲、疏水性, 在 Ag-LSC 空气电极 (孔隙率为 $32 \%, \mathrm{Ag}$ 负载量 $30 \mathrm{mg} / \mathrm{cm}^{2}$ ) 表面涂覆一 层 PTFE 溶液疏水材料, 并置于 $140^{\circ} \mathrm{C}$ 中烘干 $24 \mathrm{~h}$, 组装成锌空气电池进行电化学测试。Ag-LSC 空气 电极本身构成亲水网络, 具备电子及离子传导通道; PTFE 构成憎水网络, 控制空气电极中部分孔道不 被电解液充塞, 从而保证了空气电极中的气体扩散 通道, 氧气能顺利迁移至反应点。

图 8 为 PTFE 与 $\mathrm{LSC}$ 连接的界面 SEM 照片, 表 面 PTFE 层的厚度为 $4 \mu \mathrm{m}$, 厚度薄有利于氧气扩 散。由图 9 的输出性能图可以看出, 添加疏水材料 的阴极在同一电流密度 $5 \mathrm{~mA} / \mathrm{cm}^{2}$ 下恒流放电, 采用

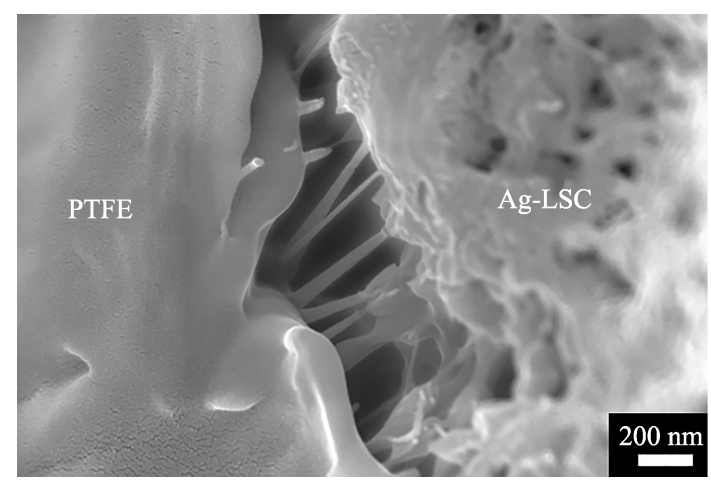

图 8 添加 PTFE 阴极的 SEM 照片

Fig. 8 SEM image of the cathode with PTFE

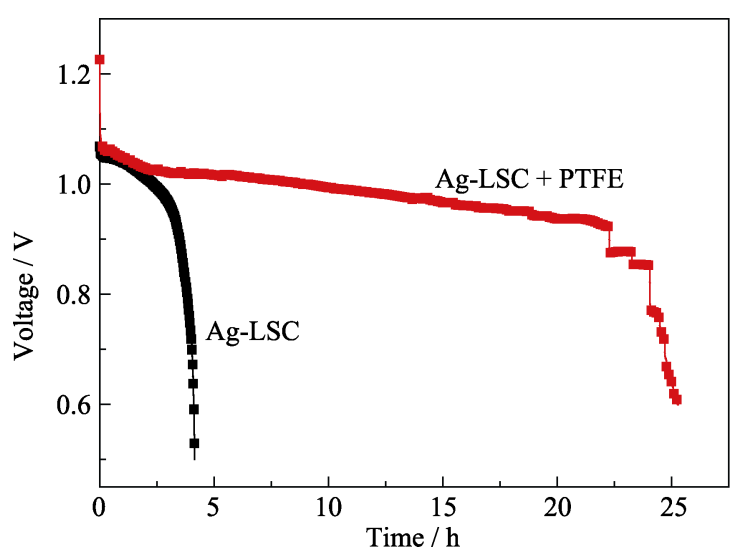

图 9 用添加与不添加 PTFE 的阴极组装的锌空气电池恒流 放电曲线图

Fig. 9 Constant current discharge curves of the zinc-air battery composed of cathode with or without PTFE 
等量的阳极锌粉，放电时间由原来 $4 \mathrm{~h}$ 左右延长到 $25 \mathrm{~h}$ 左右, 电池的使用寿命得到明显的提高, 锌空 气电池放电容量从 $20 \mathrm{~mA} \cdot \mathrm{h}$ 增大到 $125 \mathrm{~mA} \cdot \mathrm{h}$ 。电池 在相同电流密度下放电依旧维持较高的输出电压, 可见，表面 PTFE 薄层不会阻碍氧气扩散，且由 PTFE 构建的憎水网络进入 Ag-LSC 阴极, 为氧气传 质提供通道，从而提升了电极的使用寿命。

图 10 所示为锌空气电池在电池放电后更换阳 极锌粉的放电性能图。第一次放电后将锌空气电池 中的阳极材料换成新的锌粉, 在电流密度 $10 \mathrm{~mA} / \mathrm{cm}^{2}$ 下恒流放电，再次更换锌粉在电流密度 $5 \mathrm{~mA} / \mathrm{cm}^{2}$ 下 恒流放电，电池有稳定的放电平台，仍能长时间持 续放电，证明实验制备的 Ag-LSC 阴极具有优异的 稳定性。

\section{4 空气电极放电前后的性能表征}

图 11 是阴极材料放电前后的 XPS 图谱。图中 $\mathrm{Sr} 3 \mathrm{~d} 、 \mathrm{La} 3 \mathrm{~d}$ 和 $\mathrm{Co} 2 \mathrm{p}$ 的窄谱特征峰对应的位置与文 献中报道 $\mathrm{La}_{0.7} \mathrm{Sr}_{0.3} \mathrm{CoO}_{3-\delta}$ 一致 ${ }^{[36]}$, 所有峰在放电前 后都没有明显偏移，证明制备的 LSC 钙针矿基底在 电池放电过程中稳定性良好。

\section{3 结论}

采用一种新型的多孔钙钛矿 $\mathrm{La}_{0.7} \mathrm{Sr}_{0.3} \mathrm{CoO}_{3-\delta}$ (LSC) 作为陶瓷基底, 以负载银的纳米颗粒为催化 剂制备了 Ag-LSC 空气电极。以此空气电极作为阴 极，与阳极锌组装成锌空气电池，当孔隙率为 $32 \%$, 且含 $\mathrm{Ag}$ 量为 $30 \mathrm{mg} / \mathrm{cm}^{2}$ 时, 最高的功率密度达到 $141 \mathrm{~mW} / \mathrm{cm}^{2}$ 。通过在已优化的 Ag-LSC 空气电极中 添加 PTFE, 延长锌空气电池的使用寿命, 锌粉放电 结束后更换锌粉还能持续放电, 进一步证明了制备

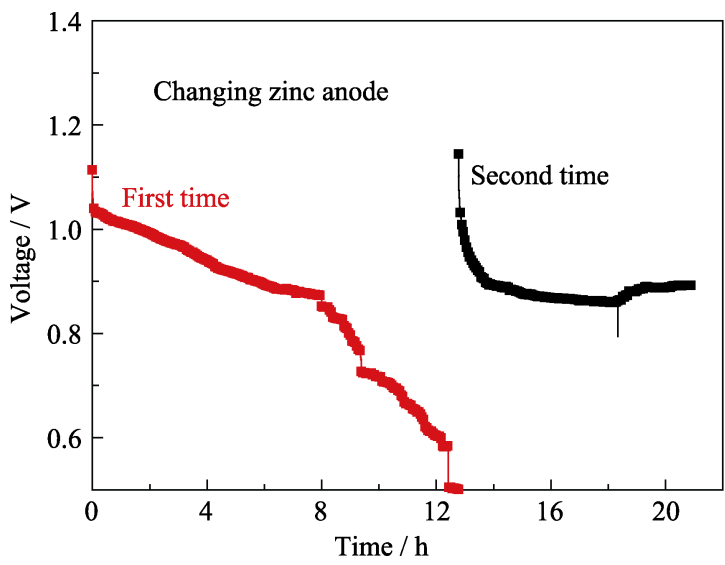

图 10 锌空气电池在电池放电后更换阳极锌粉的恒流放电 曲线图

Fig. 10 Constant current discharge curves of the zinc-air battery of changing zinc anode after discharging
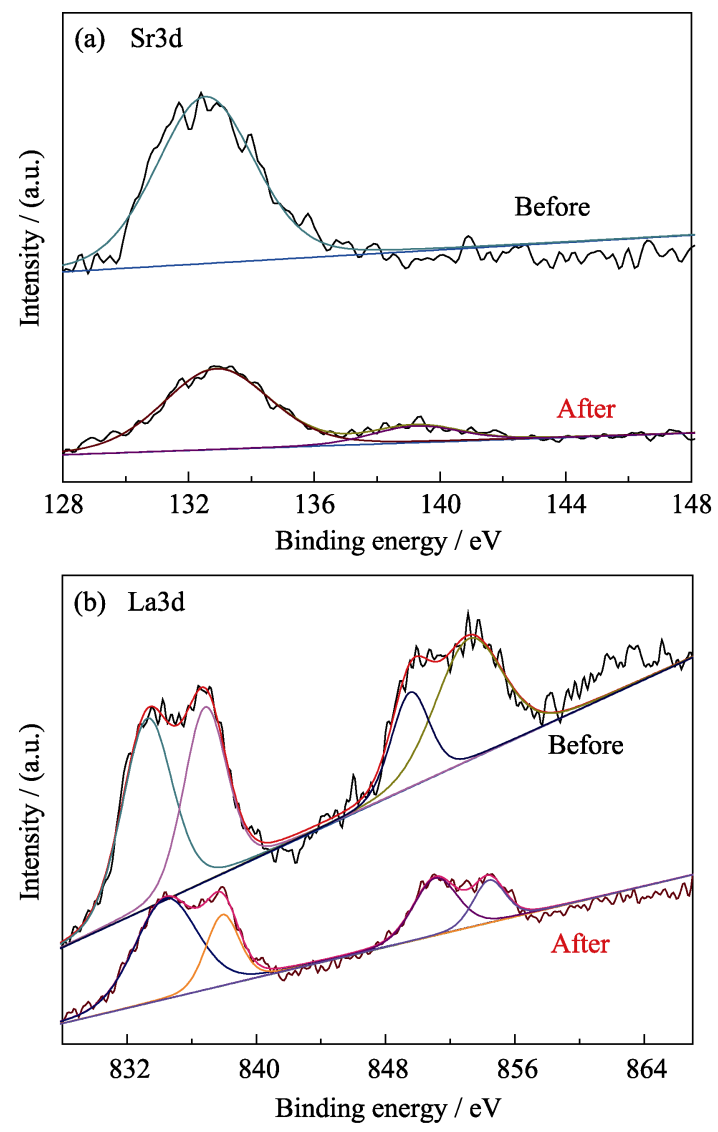

(c) $\operatorname{Co} 2 \mathrm{p}$

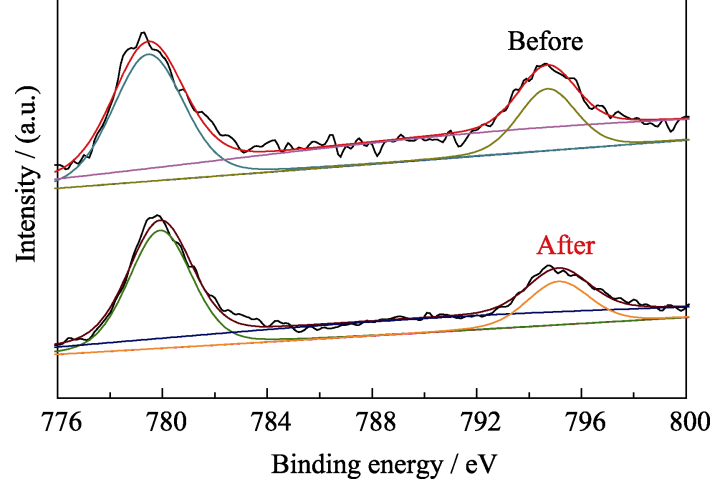

图 11 锌空气电池阴极放电前后的 XPS 能谱图

Fig. 11 XPS spectra of the cathode of zinc-air battery before and after discharging

(a) Sr3d; (b) La3d; (c) Co2p

的 Ag-LSC 用作空气电极的可行性。本研究不仅设 计了一种新型的用于锌空气电池以钙钛矿为陶瓷基 底的空气电极，并通过优化孔隙率、催化剂、疏水 剂量对空气电极进行性能改良, 具有实用价值。

\section{参考文献:}

[1] PEI P, WANG K, MA Z. Technologies for extending zinc-air battery's cyclelife: a review. Applied Energy, 2014, 128: 315-324.

[2] SAPKOTA P, KIM H. Zinc-air fuel cell, a potential candidate for alternative energy. Journal of Industrial and Engineering Chemistry, 2009, 15(4): 445-450. 
[3] LI Y, DAI H. Recent advances in zinc-air batteries. Chem. Soc. Rev., 2014, 43(15): 5257-5275.

[4] FU J, CANO Z P, PARK M G, et al. Electrically rechargeable zinc-air batteries: progress, challenges, and perspectives. Advanced materials, 2017, 29(7): 1-34.

[5] LEE J-S, TAI KIM S, CAO R, et al. Metal-air batteries with high energy density: Li-air versus Zn-air. Advanced Energy Materials, 2011, 1(1): 34-50.

[6] RAHMAN M A, WANG X, WEN C. High energy density metal-air batteries: a review . Journal of the Electrochemical Society, 2013, 160(10): A1759-A1771.

[7] WANG X, SEBASTIAN P J, SMIT M A, et al. Studies on the oxygen reduction catalyst for zinc-air battery electrode. Journal of Power Sources, 2003, 124(1): 278-284.

[8] YANG C. Preparation and characterization of electrochemical properties of air cathode electrode. International Journal of Hydrogen Energy, 2004, 29(2): 135-143.

[9] MA Z, PEI P, WANG K, et al. Degradation characteristics of air cathode in zinc air fuel cells. Journal of Power Sources, 2015, 274: $56-64$.

[10] NEBURCHILOV V, WANG H, MARTIN J J, et al. A review on air cathodes for zinc-air fuel cells. Journal of Power Sources, 2010, 195(5): 1271-1291.

[11] WANG Z L, XU D, XU J J, et al. Oxygen electrocatalysts in metal-air batteries: from aqueous to nonaqueous electrolytes. Chem Soc Rev, 2014, 43(22): 7746-7786.

[12] LEE D U, XU P, CANO Z P, et al. Recent progress and perspectives on bi-functional oxygen electrocatalysts for advanced rechargeable metal-air batteries. J. Mater. Chem. A, 2016, 4(19): $7107-7134$.

[13] FENG Y Y, ZHANG G R, MA J H, et al. Carbon-supported $\mathrm{P}^{\wedge} \mathrm{Ag}$ nanostructures as cathode catalysts for oxygen reduction reaction. Physical Chemistry Chemical Physics, 2011, 13(9): 3863-3872.

[14] LOGLIO F, LASTRAIOLI E, BIANCHINI C, et al. Cobalt monolayer islands on $\operatorname{Ag}(111)$ for ORR catalysis. ChemSusChem, 2011, 4(8): $1112-1117$

[15] XIN L, ZHANG Z, WANG Z, et al. Carbon supported Ag nanoparticles as high performance cathode catalyst for $\mathrm{H}_{2} / \mathrm{O}_{2}$ anion exchange membrane fuel cell. Frontiers in chemistry, 2013, 1(16): $1-5$.

[16] WANG Z, XIN L, ZHAO X, et al. Carbon supported Ag nanoparticles with different particle size as cathode catalysts for anion exchange membrane direct glycerol fuel cells. Renewable Energy, 2014, 62: 556-562.

[17] PECH-PECH I E, GERVASIO D F, GOD NEZ-GARCIA A, et al. Nanoparticles of $\mathrm{Ag}$ with a $\mathrm{Pt}$ and $\mathrm{Pd}$ rich surface supported on carbon as a new catalyst for the oxygen electroreduction reaction (ORR) in acid electrolytes: Part 1. Journal of Power Sources, 2015, 276(2015): 365-373.

[18] ESFANDIARI A, KAZEMEINI M, BASTANI D. Synthesis, characterization and performance determination of an $\mathrm{Ag} @ \mathrm{Pt} / \mathrm{C}$ electrocatalyst for the ORR in a PEM fuel cell. International Journal of Hydrogen Energy, 2016, 41(45): 20720-20730.

[19] WANG T, KAEMPGEN M, NOPPHAWAN P, et al. Silver nanoparticle-decorated carbon nanotubes as bifunctional gas-diffusion electrodes for zinc-air batteries. Journal of Power Sources, 2010, 195(13): 4350-4355.
[20] CHENG F, CHEN J. Metal-air batteries: from oxygen reduction electrochemistry to cathode catalysts. Chem. Soc. Rev., 2012, 41(6): 2172-2192.

[21] CAO R, LEE J S, LIU M, et al. Recent progress in non-precious catalysts for metal-air batteries. Advanced Energy Materials, 2012, 2(7): 816-829.

[22] KRAYTSBERG A, EIN-ELI Y. The impact of nano-scaled materials on advanced metal-air battery systems. Nano Energy, 2013, 2(4): 468-480.

[23] LIU P, LIU J, CHENG S, et al. A high-performance electrode for supercapacitors: silver nanoparticles grown on a porous perovskite-type material $\mathrm{La}_{0.7} \mathrm{Sr}_{0.3} \mathrm{CoO}_{3-\delta}$ substrate. Chemical Engineering Journal, 2017, 328: 1-10.

[24] GWON O, YOO S, SHIN J, et al. Optimization of $\mathrm{La}_{1-x} \mathrm{Sr}_{x} \mathrm{CoO}_{3-\delta}$ perovskite cathodes for intermediate temperature solid oxide fuel cells through the analysis of crystal structure and electrical properties. International Journal of Hydrogen Energy, 2014, 39(35): 20806-20811.

[25] WANG L, LUO X, BARBIERI D, et al. Controlling surface microstructure of calcium phosphate ceramic from random to custom-design. Ceramics International, 2014, 40(6): 7889-7897.

[26] DRILLET J F, HOLZER F, KALLIS T, et al. Influence of $\mathrm{CO}_{2}$ on the stability of bifunctional oxygen electrodes for rechargeable zinc/air batteries and study of different $\mathrm{CO}_{2}$ filter materials. Physical Chemistry Chemical Physics, 2001, 3(3): 368-371.

[27] WANG Q, LUO J, ZHONG Z, et al. $\mathrm{CO}_{2}$ capture by solid adsorbents and their applications: current status and new trends. Energy Environ. Sci., 2011, 4(1): 42-55.

[28] HAN J J, LI N, ZHANG T Y. Ag/C nanoparticles as an cathode catalyst for a zinc-air battery with a flowing alkaline electrolyte. Journal of Power Sources, 2009, 193(2): 885-889.

[29] HU J, LIU Q, SHI L, et al. Silver decorated $\mathrm{LaMnO}_{3}$ nano$\mathrm{rod} /$ graphene composite electrocatalysts as reversible metal-air battery electrodes. Applied Surface Science, 2017, 402: 61-69.

[30] HE Q, YANG X, CHEN W, et al. Influence of phosphate anion adsorption on the kinetics of oxygen electroreduction on low index Pt(hkl) single crystals. Physical Chemistry Chemical Physics, 2010, 12(39): 12544-12555.

[31] INABA M, ANDO M, HATANAKA A, et al. Controlled growth and shape formation of platinum nanoparticles and their electrochemical properties. Electrochimica Acta, 2006, 52(4): 1632-1638.

[32] LIMA F H B, DE CASTRO J F R, TICIANELLI E A. Silvercobalt bimetallic particles for oxygen reduction in alkaline media. Journal of Power Sources, 2006, 161(2): 806-812.

[33] YU A, LEE C, LEE N S, et al. Highly efficient silver-cobalt composite nanotube electrocatalysts for favorable oxygen reduction reaction. ACS applied materials \& interfaces, 2016, 8(48): 3283332841.

[34] WU X, CHEN F, ZHANG N, et al. Activity trends of binary silver alloy nanocatalysts for oxygen reduction reaction in alkaline media. Small, 2017, 13(15): 1-8.

[35] CHO YB, MOON S, LEE C, et al. One-pot electrodeposition of cobalt flower-decorated silver nanotrees for oxygen reduction reaction. Applied Surface Science, 2017, 394: 267-274.

[36] WANG P, YAO L, WANG M, et al. XPS and voltammetric studies on $\mathrm{La}_{1-x} \mathrm{Sr}_{x} \mathrm{CoO}_{3-\delta}$ perovskite oxide electrodes. Journal of Alloys and Compounds, 2000, 311: 53-56. 